\title{
A randomised double blind clinical trial to compare surgical field bleeding during endoscopic sinus surgery with clonidine-based or remifentanil-based hypotensive
} anaesthesia*

\author{
A. Cardesín', C. Pontes², R. Rosell', Y. Escamilla1', J. Marco³, M.J. Escobar ${ }^{3}$, \\ M. Bernal-Sprekelsen ${ }^{4}$ \\ ' Rhinology Unit, Dept. of Otorhinolaryngology, Hospital de Sabadell, Institut Universitari Parc Taulí, Universitat Autònoma de \\ Barcelona, Sabadell (Barcelona), Spain \\ ${ }^{2}$ Clinical Pharmacology Unit, Hospital de Sabadell, Institut Universitari Parc Taulí, Universitat Autònoma de Barcelona, Sabadell \\ (Barcelona), Spain \\ ${ }^{3}$ Dept. of Anaesthesia, Hospital de Sabadell, Institut Universitari Parc Taulí, Universitat Autònoma de Barcelona, Sabadell \\ (Barcelona), Spain \\ ${ }^{4}$ Dept. of Otorhinolaryngology, Hospital Clinic, University of Barcelona Medical School, Barcelona, Spain
}

Rhinology 53: 107-115, 2015

DOl:10.4193/Rhino14.185

*Received for publication:

August 17, 2014

Accepted: October 2, 2014

\begin{abstract}
Background: Significant bleeding during functional endoscopic naso-sinusal surgery (FESS) impairs recognition of anatomical references and may negatively affect surgical outcome. Anaesthesia including clonidine as an adjuntive hypotensive agent may reduce intraoperative bleeding.
\end{abstract}

Methods: A randomised comparison of clonidine-based vs remifentanil-based hypotensive anaesthetic regimen was conducted in patients undergoing FESS. The main assessment was the proportion of subjects with Boezaart scores of surgical field bleeding, as blindly assessed from video recordings by a third surgeon not involved in patient care.

Results: A total of 47 subjects underwent FESS and were randomised to clonidine or remifentanil. A significantly lower proportion of patients in the clonidine arm had blindly-assessed Boezaart scores higher than 2, with significantly lower mean blind Boezaart scores at 60 minutes and at 120 minutes. Similar findings were reported by the operating surgeon, and when Wormald and VAS scores were used. Objective estimates of bleeding and the duration of surgery and anaesthesia did not differ between groups.

Conclusion: The use of clonidine- based controlled hypotensive anaesthesia achieves lower surgical field bleeding during FESS.

Keywords: Functional Endoscopic Sinus Surgery, bleeding, clonidine, blood loss, general anaesthesia

\section{Introduction}

During functional endoscopic sinus surgery (FESS), one of the most important factors determining the efficacy of the technique and the potential development of surgical complications is bleeding. Excessive bleeding compromises surgical field visibility, impedes the identification of anatomical landmarks and increases the risk of harming the surrounding structures. Uncontrolled bleeding also significantly increases surgical time ${ }^{(1,2)}$. Several approaches have been tested to reduce intraope- rative bleeding, including raising the patient's head to reduce orthostatic blood pressure, the use of preoperative corticosteroids to reduce inflammation, injection of adrenaline in the diseased mucosa prior to surgery, administration of intravenous or topical tranexamic acid and even repeated packing with cottonoids soaked in adrenaline during surgery ${ }^{(3-7)}$. Additionally, several physiological factors such as arterial blood pressure, heart rate, thrombopenia, and coagulation disorders have been associated with the extent of perioperative bleeding and require 
prior medical management. In this context, appropriate patient positioning and controlled doses of general anaesthetic agents allow satisfactory haemodynamic management during surgery $(8,9)$, reducing blood loss and optimizing the surgical field. Hypotensive general anaesthesia achieves controlled short-term hypotension, with minimal toxicity and preservation of cerebrovascular blood flow and autoregulation ${ }^{(10)}$.

Among the most frequently used hypotensive anaesthetic agents are opioid agonists like fentanyl or remifentanil, or central acting agents like clonidine. Clonidine is an a-2-adrenergic agonist that reduces blood pressure by decreasing the peripheral sympathetic discharge. It has been widely used because of its well-known advantages in haemodynamic management during general anaesthesia and its favourable risk/benefit relationship (11-16), and also as a pre-medication before total intravenous anaesthesia to improve surgical field visualization. For their part, fentanyl and remifentanil are selective agonists of $\mu$ opioid receptors. These agents are fast-acting and have a short half-life $(17,18)$.

Both types of agent have been extensively used in conventional general anaesthesia. Previous clinical reports have identified major differences between them, suggesting better results with clonidine-based regimens, although these observations have not been adequately analysed in systematic clinical studies ${ }^{(19-21)}$. Previously, our group carried out an initial observational cohort study including 37 consecutive patients undergoing FESS who received either clonidine or opioid-based hypotensive anaesthetic regimens, according to the anaesthetist's preferences. Assessing surgical field bleeding with the Boezaart bleeding scale, we found that patients who received clonidine-based hypotensive anaesthesia presented significantly lower scores. According to a multivariate analysis adjusted for baseline risk factors for bleeding, the differences were explained mostly by the type of anaesthesia received ${ }^{(22)}$.

Based on the encouraging results of that pilot study, we designed a prospective, randomised, double-blind clinical trial with the aim of obtaining robust clinical evidence of the differential effect of clonidine versus an opioid-based anaesthetic regimen on surgical field bleeding during FESS.

\section{Materials and methods}

A randomised, double-blind trial was designed to compare intraoperative surgical field bleeding with clonidine- or remifentanil-based anaesthetic regimens. Our working hypothesis was that the use of the alpha2-adrenergic drug clonidine as a hypotensive agent in a total intravenous anaesthesia (TIVA) regimen would reduce intraoperative surgical field bleeding and improve visibility during FESS interventions compared with a remifentanil-based TIVA regimen. The study was conducted at two different settings (Hospital de Sabadell, Sabadell, Barcelona, and Clínica del Vallés, Sabadell, Barcelona).

\section{Patients}

Patients were eligible if they were aged 18 years or older, were programmed for FESS due to chronic rhinosinusitis (CRS) \pm nasal polyposis, had an ASA score (American Society of Anesthesiologists Physical Status Scale Ratings) I-III, and provided signed informed consent. Patients were excluded if they had contraindications for either FESS or any of the studied anaesthetic regimens, presented coagulation disorders, previous history of coronary arteriopathy, stroke or arrhythmia, or had recently received adrenergic or calcium channel blockers ("recent" being considered as a period of less than seven half-lives of the drug). Randomisation to each of the arms was done in blocks and stratified by the centre where surgery was performed and according to the indication for surgery (chronic rhinosinusitis with or without nasal polyposis). Individual sealed codes were prepared at the Clinical Pharmacology Department according to a randomisation list, using the Winpepi version 2.67 - Etcetera: Balanced stratified [module A4] ${ }^{(23)}$. The list and a copy of the codes were kept safely and separately in a file that was not accessible either to surgeons or to anaesthetists. Patients were randomly allocated on arriving in the operating room by the anaesthetist, who opened the first available sequentially numbered sealed code within the patient stratum. Treatment allocation was open for the anaesthesiologist and blind for the surgeon.

\section{Treatments}

Treatment consisted of either a single intravenous dose of 1 to 1.5 micrograms $(\mu \mathrm{g})$ per kilogram $(\mathrm{kg})$ of clonidine in saline infusion 20 minutes before the initiation of the surgery, or a continuous perfusion of 0.1 to $0.2 \mu \mathrm{g}$ per $\mathrm{kg}$ and minute ( $\mathrm{min}$ ) of remifentanil during the procedure. In addition to the treatments studied, patients received anaesthesia according to the centre's standardized local protocols, consisting of a balanced anaesthetic induction with 4 milligrams $(\mathrm{mg})$ per $\mathrm{kg}$ of propofol and 2-3 $\mu \mathrm{g}$ per $\mathrm{kg}$ of fentanyl, a non-depolarising neuromuscular blocking drug, and anaesthetic maintenance with sevofluorane. Premedication included $4 \mathrm{mg}$ of dexamethasone and ondansetron as prophylaxis of nausea and vomiting, and midazolam in some cases at the discretion of the anaesthesiologist. All patients received intraoperative prophylaxis with a single dose of $1 \mathrm{~g}$ co-amoxiclav (or 300-600mg of clindamycin in case of allergy to betalactams). Our standard routine protocols do not include any preoperative anti-inflammatory medication.

\section{Assessments}

Blood loss was evaluated by the operating surgeon (blinded) and an external rhinologist (blinded) who reviewed the complete records of the surgical intervention. 
Every 60 minutes, intraoperative bleeding was measured by the operating surgeon using three subjective methods: the Boezaart ${ }^{(24)}$ and Wormald ${ }^{(25)}$ surgical field bleeding scores, and a visual analogue scale (VAS). Interventions were also video-taped with a camera coupled to the endoscope, and sent in batches of ten recordings to an external investigator who was blinded to patient and treatment identity for evaluation of bleeding using the Boezaart and Wormald scores and the VAS at the predefined time points. The main variable was the proportion of patients with intense bleeding, defined as a mean Boezaart score above 2 during surgery as assessed by the external investigator. Other objective outcome measures included the estimated amount of blood loss, derived from the volume and haematocrit of the fluid aspirated during surgery. This value was corrected by the patient's mean haematocrit, according to the formula $\mathrm{Hba}(\mathrm{g} \mathrm{dl}-1) \times \mathrm{V}(\mathrm{ml}) / \mathrm{Hbm}$ ( $\mathrm{g} \mathrm{dl}-1)$, where Hba represents the haematocrit of the fluid aspirated from the surgical field, $V$ the total volume of the aspirated fluid and $\mathrm{Hbm}$ the patient's mean haematocrit, considering pre- and post-operative values ${ }^{(26)}$. Total surgical and anaesthesia time, haemodynamic parameters (systolic and diastolic blood pressure (SBP and DBP), mean blood pressure (MBP) and heart rate (HR) were measured every $15 \mathrm{~min}$, and ventilation ( $\mathrm{CO}_{2}$ at the end of procedure). Adverse events (complications) were also registered. Other potentially relevant baseline characteristics for prognosis were recorded, including sinus occupancy based on the Lund-Mackay scale (0-24 points) ${ }^{(27)}$, extent of disease (polyposis grading I to IV), presence or absence of Samter's triad, previous history of asthma, concurrent pharmacological treatment and other medical diseases. Patients were followed until hospital discharge and one week later. Postoperative clinical outcomes included time to patient discharge, need to return to hospital for surgery-related complications, need for reoperation, and any late adverse events.

\section{Statistical analysis}

The main variable, the dichotomised mean Boezaart value [2 or lower vs higher than 2] as assessed by the external surgeon was compared using a Fisher exact test for differences between groups and considering the randomisation strata; the comparison was also done using only the worst bleeding score for each patient.

Qualitative variables were described by the number of valid values and the frequency and percentage of each category, and compared between groups using Fisher exact tests. Quantitative variables were described by measures of central tendency and dispersion, and compared between groups using Mann-Whitney's test. Variables measured at different time points (Boezaart and Wormald scales each 60 minutes and SBP, DBP, MBP and HR every 15 minutes during the intervention) were analysed using a stratum- and baseline-adjusted repeated measurement analysis for each time point. The main analysis was done by intention to

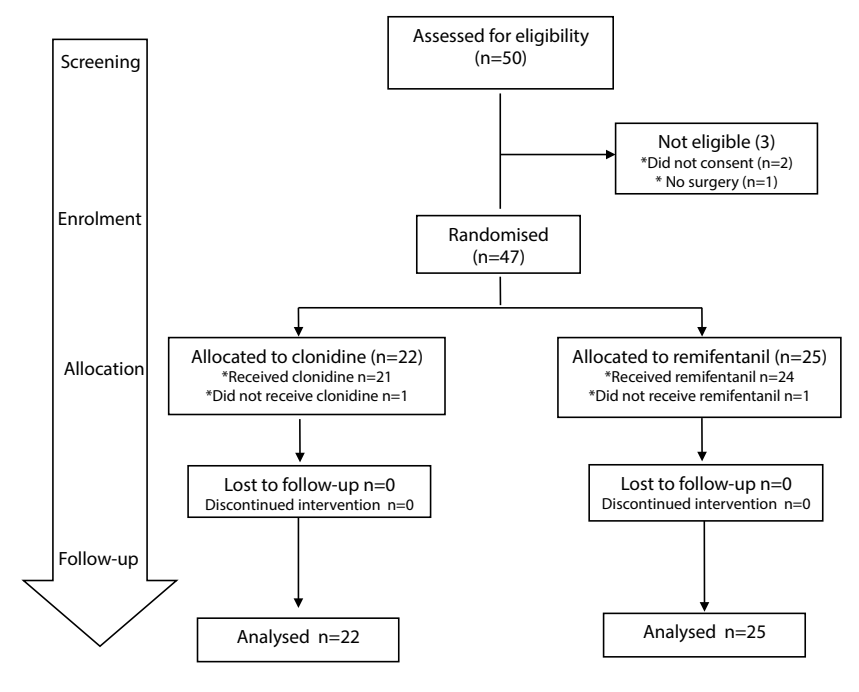

Figure 1. CONSORT diagram.

treat (ITT), using the full analysis set; a sensitivity analysis using only patients who adhered to the protocol was also performed for the principal and key secondary variables.

\section{Ethics}

The study was authorised by the corresponding Independent Ethics Committee and by the Spanish Agency of Medicines and Medical Devices prior to the inclusion of the first patient in the study, and was conducted in accordance with the ethical standards laid down in the Declaration of Helsinki (updated October 2013, Fortaleza, Brazil) and with the standards of the International Conference on Harmonization of Good Clinical Practice. After a full explanation of the study, all patients were asked to give informed consent prior to enrolment. Data forms were coded and dissociated data were used for analysis.

\section{Results}

All consecutive subjects undergoing elective FESS for CRS \pm polyposis in two separate settings between March 2012 and March 2013 ( $n=50$ ) were assessed for eligibility. Out of 50 cases, two did not consent to participate and one finally did not undergo surgery. The remaining 47 subjects were randomised. Figure 1 summarises the patient eligibility flow. There were no significant differences in baseline characteristics between the groups, and in particular in the type of anaesthesia or the surgical complexity prognosis as assessed by mean (SD) Lund-Mackay scores, which were 11.9 (6.9) in clonidine vs 13.0 (7.0) remifentanil ( $p$ $=0.546$ ). The most frequent indication for surgery was CRS \pm polyposis ( $n=15$ patients in the clonidine arm and 17 in the remifentanil arm); most procedures involve the posterior ethmoid \pm sphenoid ( $n=14$ in the clonidine arm and $n=17$ in the remifentanil arm), and only a few cases ( $n=2$ in the clonidine arm and $n=4$ in the remifentanil arm) were secondary revision sur- 
Table 1. Baseline characteristics of the patients.

\begin{tabular}{|c|c|c|}
\hline & $\begin{array}{l}\text { Clonidine } \\
(n=22)\end{array}$ & $\begin{array}{l}\text { Remifentanil } \\
\quad(n=25)\end{array}$ \\
\hline Sex (male) & $15(68.2 \%)$ & $14(56.0 \%)$ \\
\hline Age (Mean \pm SD) & $48.3(13.4)$ & $47.1(12.1)$ \\
\hline BMI (Mean \pm SD) & $26.37(5.07)$ & $26.37(5.25)$ \\
\hline Asthma antecedent & $3(13.6 \%)$ & $8(32.0 \%)$ \\
\hline Samter's triad & $1(4.5 \%)$ & $4(16.0 \%)$ \\
\hline \multicolumn{3}{|l|}{ ASA class } \\
\hline 1 & $2(9.5 \%)$ & $2(8.0 \%)$ \\
\hline 2 & $18(85.7 \%)$ & $21(84.0 \%)$ \\
\hline 3 & $1(4.8 \%)$ & $2(8.0 \%)$ \\
\hline NA & $1(4.8 \%)$ & $0(0.0 \%)$ \\
\hline \multicolumn{3}{|l|}{ Surgical indication } \\
\hline CRS & $7(31.8 \%)$ & $8(32.0 \%)$ \\
\hline \multicolumn{3}{|l|}{ CRS + polyposis } \\
\hline Grade I & $0(0.0 \%)$ & $2(8.0 \%)$ \\
\hline Grade II & $6(27.3 \%)$ & $3(12.0 \%)$ \\
\hline Grade III & $4(18.2 \%)$ & $7(28.0 \%)$ \\
\hline Grade IV & $5(22.7 \%)$ & $5(20.0 \%)$ \\
\hline Lund-Mackay score (mean ( \pm SD) & $11.9(6.9)$ & $13.0(7.0)$ \\
\hline \multicolumn{3}{|l|}{ Type of FESS } \\
\hline Anterior, with medial meatotomy & $8(36.4 \%)$ & $8(32.0 \%)$ \\
\hline Posterior, ethmoidal \pm sphenoidal & $14(63.6 \%)$ & $17(68.0 \%)$ \\
\hline Primary surgery & $20(90.9 \%)$ & $21(84.0 \%)$ \\
\hline Secondary surgery & $2(9.1 \%)$ & $4(16.0 \%)$ \\
\hline
\end{tabular}

ASA: American Society of Anaesthesia; BMI: body mass index; CRS: Chronic rhinosinusitis; NA: not available.

geries. Table 1 summarises the main characteristics of the study population. Five surgeons and two anaesthetists were involved in patient care and assessments, and a sixth surgeon took part in the evaluation of video-recordings of the FESS.

In the ITT analysis of the primary endpoint, significant differences were observed between treatments in the proportion of patients who had a mean Boezaart bleeding score $>2$ (intense bleeding), as assessed from video recordings by a blinded surgeon $(n=4 ; 18.2 \%)$ in the clonidine arm vs $(n=13 ; 52.0 \%)$ in the

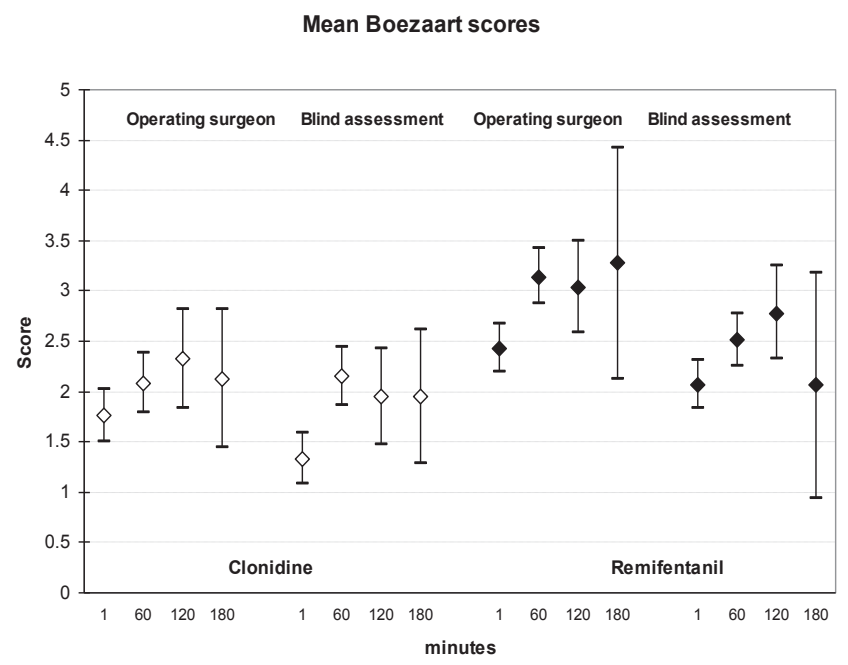

Figure 2. Main efficacy outcomes.

remifentanil arm, with a difference $(95 \% \mathrm{Cl}$ ) of $33.8 \%$ (range $8.5 \%$ to $59.2 \%$ ). Similar results were observed in the stratified analysis, and also when the worst value recorded per patient during surgery was used instead of the mean value $((n=5 ; 22.7 \%)$ in the clonidine arm vs $(n=15 ; 60.0 \%)$ in the remifentanil arm, with a difference of $37.3 \%$ (range: $11.3 \%$ to $63.6 \%$ ))(Table 2). The analysis of the mean bleeding values at different times, carried out with the Boezaart or Wormald scales by the operating surgeon or by the external blinded investigator, showed significant differences from the start of the procedure until the second hour of surgery, but not in the assessment after three hours. The VAS assessments were less sensitive and showed differences only at certain points (Table 2 and Figure 2).

In general, the analysis of haemodynamic parameters showed low values for SBP, DBP and MBP during surgery in both groups. Significantly higher values were observed in the clonidine arm for SBP at 01:15 hours and for DBP, MBP and HR at 00:30 and 00:45 hours. Heart rate followed a similar pattern (Figure $3 \mathrm{~b}$ ). The duration of surgery and final $\mathrm{CO}_{2}$ did not differ between groups; no difference in the rate of postoperative bleeding or complications was observed (Table 3 ). The results were similar when only patients treated according to the protocol were considered ( $n=45 ; 21$ in the clonidine arm and 24 in the remifentanil arm) (data not shown).

\section{Discussion}

Hypotensive controlled anaesthesia has yielded promising results in bleeding control during FESS. Previous studies have reported differences between hypotensive anaesthesia based either on opioid antagonists like fentanyl or remifentanil, or on central acting agents like clonidine ${ }^{(19-21)}$. The evidence suggests that clonidine and other a 2 agonists like dexmedetomidine 
Table 2. Bleeding outcomes during surgery.

\begin{tabular}{|c|c|c|c|c|c|}
\hline \multicolumn{2}{|l|}{ 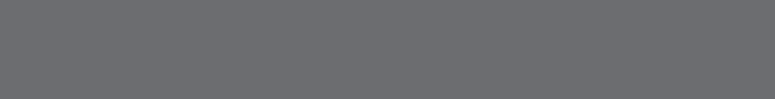 } & $\begin{array}{l}\text { Clonidine } \\
(\mathbf{n}=22)\end{array}$ & $\begin{array}{l}\text { Remifentanil } \\
\qquad(\mathrm{n}=\mathbf{2 5})\end{array}$ & $\begin{array}{l}\text { Difference } \\
95 \% \mathrm{Cl}\end{array}$ & p-value \\
\hline \multicolumn{6}{|l|}{ Primary end-point } \\
\hline \multicolumn{2}{|c|}{ Intense (>2 ) mean Boezaart bleeding score during surgery, blind } & $4(18.2 \%)$ & $13(52.0 \%)$ & $\begin{array}{c}33.8 \% \\
(8.5 \% \text { to } 59.2 \%)\end{array}$ & 0,032 \\
\hline \multicolumn{2}{|c|}{$\begin{array}{l}\text { Intense }(>2) \text { worst reported Boezaart bleeding score during } \\
\text { surgery, blind }\end{array}$} & $5(22.7 \%)$ & $15(60.0 \%)$ & $\begin{array}{c}37.3 \% \\
(11.3 \% \text { to } 63.6 \%)\end{array}$ & 0,017 \\
\hline \multicolumn{6}{|c|}{ Boezaart bleeding scores (Mean, [95\% Cl]) } \\
\hline \multirow[t]{2}{*}{$1 \mathrm{~min}$} & Surgeon & $1.77[1.50 ; 2.03]$ & $2.43[2.19 ; 2.68]$ & $-0.67[-1.02 ;-0.31]$ & 0,001 \\
\hline & External reviewer & $1.33[1.08 ; 1.59]$ & $2.07[1.83 ; 2.31]$ & $-0.73[-1.07 ;-0.39]$ & 0,001 \\
\hline \multirow[t]{2}{*}{$60 \mathrm{~min}$} & Surgeon & $2.08[1.79 ; 2.38]$ & $3.14[2.87 ; 3.42]$ & $-1.06[-1.45 ;-0.67]$ & 0,001 \\
\hline & External reviewer & $2.16[1.87 ; 2.44]$ & $2.51[2.25 ; 2.77]$ & $-0.35[-0.73 ; 0.02]$ & 0,066 \\
\hline \multirow[t]{2}{*}{$120 \mathrm{~min}$} & Surgeon & $2.33[1.84 ; 2.82]$ & $3.04[2.59 ; 3.49]$ & $-0.71[-1.35 ;-0.07]$ & 0,031 \\
\hline & External reviewer & $1.95[1.48 ; 2.43]$ & $2.78[2.32 ; 3.25]$ & $-0.83[-1.47 ;-0.19]$ & 0,013 \\
\hline \multirow[t]{2}{*}{$180 \mathrm{~min}$} & Surgeon & $2.13[1.45 ; 2.82]$ & $3.28[2.13 ; 4.42]$ & $-1.15[-2.47 ; 0.17]$ & 0,087 \\
\hline & External reviewer & $1.95[1.29 ; 2.61]$ & $2.06[0.94 ; 3.18]$ & $-0.11[-1.39 ; 1.17]$ & 0,862 \\
\hline \multicolumn{6}{|c|}{ Wormald scale scores for bleeding (Mean, [95\% Cl]) } \\
\hline \multirow[t]{2}{*}{$1 \mathrm{~min}$} & Surgeon & $2.29[1.58 ; 3.00]$ & $3.38[2.72 ; 4.04]$ & $-1.09[-2.04 ;-0.15]$ & 0.025 \\
\hline & External reviewer & $1.54[1.17 ; 1.90]$ & $2.46[2.12 ; 2.81]$ & $-0.92[-1.41 ;-0.43]$ & 0.001 \\
\hline \multirow[t]{2}{*}{$60 \mathrm{~min}$} & Surgeon & $2.43[1.65 ; 3.21]$ & $5.35[4.63 ; 6.08]$ & $-2.92[-3.97 ;-1.88]$ & 0.001 \\
\hline & External reviewer & $2.33[1.93 ; 2.73]$ & $3.14[2.76 ; 3.51]$ & $-0.80[-1.34 ;-0.27]$ & 0.004 \\
\hline \multirow[t]{2}{*}{$120 \mathrm{~min}$} & Surgeon & $2.68[1.38 ; 3.98]$ & $5.32[4.13 ; 6.51]$ & $-2.64[-4.35 ;-0.93]$ & 0.003 \\
\hline & External reviewer & $2.41[1.77 ; 3.05]$ & $3.37[2.75 ; 4.00]$ & $-0.97[-1.84 ;-0.09]$ & 0.031 \\
\hline \multirow[t]{2}{*}{$180 \mathrm{~min}$} & Surgeon & $2.60[0.77 ; 4.43]$ & $4.61[1.56 ; 7.66]$ & $-2.01[-5.53 ; 1.51]$ & 0.256 \\
\hline & External reviewer & $2.01[1.11 ; 2.91]$ & $3.13[1.64 ; 4.62]$ & $-1.12[-2.85 ; 0.60]$ & 0.197 \\
\hline \multicolumn{6}{|c|}{ Visual analogue scales for bleeding (Mean, [95\% Cl]) } \\
\hline \multirow[t]{2}{*}{$1 \mathrm{~min}$} & Surgeon & $2.42[1.68 ; 3.17]$ & $3.34[2.67 ; 4.02]$ & $-0.92[-1.90 ; 0.06]$ & 0,066 \\
\hline & External reviewer & $1.07[0.63 ; 1.51]$ & $1.61[1.19 ; 2.03]$ & $-0.54[-1.13 ; 0.05]$ & 0,072 \\
\hline \multirow[t]{2}{*}{$60 \mathrm{~min}$} & Surgeon & $2.77[1.97 ; 3.57]$ & $5.17[4.43 ; 5.90]$ & $-2.40[-3.46 ;-1.33]$ & 0,001 \\
\hline & External reviewer & $1.77[1.30 ; 2.25]$ & $2.34[1.90 ; 2.79]$ & $-0.57[-1.21 ; 0.06]$ & 0,076 \\
\hline \multirow[t]{2}{*}{$120 \mathrm{~min}$} & Surgeon & $3.13[1.84 ; 4.42]$ & $5.19[4.00 ; 6.37]$ & $-2.05[-3.76 ;-0.35]$ & 0,019 \\
\hline & External reviewer & $1.64[0.93 ; 2.36]$ & $2.57[1.87 ; 3.27]$ & $-0.92[-1.90 ; 0.05]$ & 0,062 \\
\hline \multirow[t]{2}{*}{$180 \mathrm{~min}$} & Surgeon & $3.83[2.00 ; 5.67]$ & $7.15[4.13 ; 10.16]$ & $-3.31[-6.80 ; 0.17]$ & 0,062 \\
\hline & External reviewer & $1.42[0.22 ; 2.61]$ & $1.74[0.12 ; 3.37]$ & $-0.33[-2.32 ; 1.67]$ & 0,743 \\
\hline \multicolumn{6}{|c|}{ Calculated blood loss volume $(\mathrm{mL})(\mathrm{Hba}(\mathrm{g} \mathrm{dl}-1) \times \mathrm{V}(\mathrm{ml}) / \mathrm{Hbm}(\mathrm{g} \mathrm{dl}-1))$} \\
\hline Estimated volume (mean, $[95 \% \mathrm{Cl}]$ ) & & $148.91(175.19)$ & $116.26(88.29)$ & & 0,821 \\
\hline
\end{tabular}

Hba: haematocrit of the fluid aspirated from the surgical field, V: total volume of aspirated fluid; Hbm: mean haematocrit, considering pre- and postoperative values. 

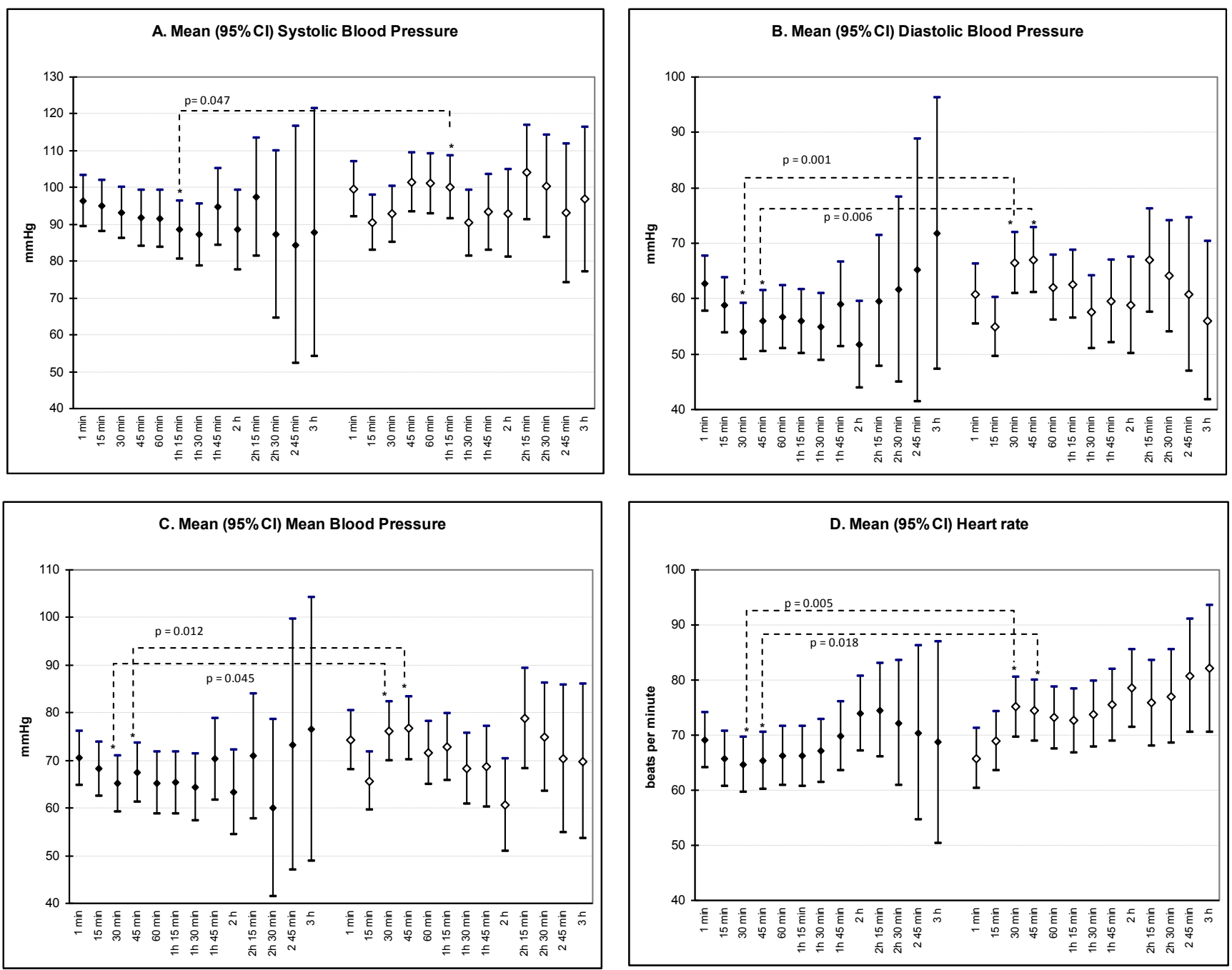

Figure 3. Vital signs during anaesthesia.

have a more favourable pharmacological profile, which offers better, more controlled haemodynamic management, with an optimized hypotensive effect during anaesthesia that allows safe bleeding control ${ }^{(28-31)}$. In our previous observational cohort pilot study, we recorded a trend towards a better haemodynamic profile and heart rate estimates, lower bleeding scores and reduced surgery duration with clonidine as compared to an opioid-based regimen ${ }^{(22)}$. The purpose of the present study was to confirm these results in a randomised double-blind clinical trial in order to generate robust, consistent evidence of the role of clonidine in FESS compared with the opioid agonist remifentanil.

The main study outcome - the proportion of patients with a mean Boezaart value higher than 2 (intense bleeding) - showed statistically significant differences. Intense bleeding was recorded in $52 \%$ of remifentanil patients, but only in $18.2 \%$ of clonidine patients. These differences were consistently observed when comparing the mean Boezaart and Wormald scales, mainly in the first two hours of surgery. Patients included in the trial had relatively high preoperative Lund-Mackay scores (mean values $>12$ ), due to the fact that bilateral CRS with polyposis refractory to medical treatment was the most frequent indication for surgery, although there were no baseline differences between groups. As bilateral surgery for polyposis and LundMackay scores higher than 12 are both independent risk factors for intense bleeding during FESS (27,32), our study population can be considered as high risk for suffering increased intraoperative bleeding, and thus appropriate for the assessment of the efficacy of clonidine as a hypotensive anaesthetic agent. Our observation of a significant effect can therefore be considered clinically relevant.

The fact that the anaesthetist was in charge of randomisation and was thus aware of the identity of the treatment could be regarded as a potential bias, because bleeding was assessed using subjective measurement scales (Boezaart, Wormald and VAS). However, these scales have been used in previous studies 
Table 3. Outcomes of anaesthesia and surgery.

\begin{tabular}{|lcc|}
\hline & Clonidine (n= 22) & Remifentanil (n= 25) \\
\hline Duration of anaesthesia (Mean \pm SD) & $143.59(51.76)$ & $127.68(39.95)$ \\
\hline Duration of surgery (Mean \pm SD) & $109.43(51.70)$ & $02.32(40.48)$ \\
\hline Final $\mathrm{CO}_{2}$ (Mean \pm SD) & $35.29(4.53)$ & $33.36(4.20)$ \\
\hline Postoperative bleeding & $4(19.0 \%)$ & 0.326 \\
\hline Visit to emergency ward after discharge & $1(4.8 \%)$ & 0.092 \\
\hline Need for unscheduled medical attention & $3(14.3 \%)$ & $3(12.0 \%)$ \\
\hline Need for surgical reintervention & $1(4.8 \%)$ & 1.457 \\
\hline
\end{tabular}

$(3,11,24,25)$ and were therefore considered adequate for our trial. In addition, the study was designed as a blinded, independent external review of video recordings with assessment of the surgical field at predefined time points. As a result, internal and external assessment yielded similar results with a high grade of concordance.

Bleeding volume was calculated from the volume of the surgical aspirate by the haematocrit of the liquid and that of the patient, using a mean of pre- and post-operative haematocrit values ${ }^{(20)}$. However, the haematocrit value of the aspirate was highly variable, often below $1 \%$, thus providing disparate values which did not prove sensitive enough to detect differences between treatments.

As expected, haemodynamic parameters showed sustained intraoperative hypotension with no substantial differences between the two types of anaesthesia, except for higher MBP, $\mathrm{DBP}$ and $\mathrm{HR}$ at 30 and 45 minutes with clonidine (Figure 3 ). Opioids are vasodilating agents that induce hypotension via histamine and nitrous oxide release at the vascular level. They may also have a direct effect on vascular smooth muscles inducing arteriolar vasodilation ${ }^{(33)}$. Clonidine is an alpha2-adrenergic agonist, acting mainly in the central nervous system, where the stimulation of alpha-2 receptors induce a peripheral arterial vasodilation. However, as an agonist administered intravenously, clonidine might also have some non-specific alpha agonist vasoconstriction properties at the peripheral level. This might explain why it is less likely to induce capillary vasodilation in tissues and is thus able to reduce surgical field bleeding ${ }^{(34,35)}$.

The effect on surgical field bleeding scores was substantial and significantly higher in the clonidine group in the first two hours of the procedure, but the differences were not evident at later time points. This may be due to the fact that most procedures lasted less than three hours, resulting in a small number of observations from two hours onwards; but it may also be due to a decline in the effect of clonidine, which would parallel the changes in haemodynamic parameters at later time points.

Thus, the results suggest that the best results of clonidine-based regimens could be expected in the first two hours of the surgical procedure.

Another possible explanation may be the delayed activation of a1 receptors observed when high doses of clonidine are administered. This pharmacological effect has been previously described in pharmacodynamic and pharmacokinetic characterization studies of clonidine, and also in clinical reports of acute adverse events deriving from dosage errors which led to the administration of acute high doses of this agent ${ }^{(36)}$. Following this pharmacological rationale, the subsequent increase in haemodynamic estimates by the end of the surgical procedure may reflect a transient and time-dependent activation of the a1 receptors. In any case, the two processes may act simultaneously, generating the dynamic evolution in haemodynamic estimates that we observed in our trial ${ }^{(12,36,37)}$.

Although a reduction in bleeding in the surgical field was observed, neither the duration of surgery and anaesthesia nor total blood volume loss showed significant differences between the two groups. This finding is at odds with some previous observations ${ }^{(22,36,38)}$, but is consistent with other studies in which improvements in the quality of the surgical field did not shorten the duration of the procedure ${ }^{(3)}$. Leaving aside the intersubject variability in these determinations, the randomised nature of the present study makes our results more robust than those obtained with observational designs. Our results may indicate that changes in perceived visibility in the surgical field do not have a substantial direct effect on surgical duration or on outcomes. We should also mention that the present study has a modest sample size, designed to detect differences in surgical field bleeding; with a larger sample size we might have been able to detect smaller but nonetheless clinically relevant differences in these parameters. 


\section{Conclusions}

In summary, the present clinical trial has shown a significant decrease in bleeding scores with clonidine-based anaesthetic regimens compared with a remifentanil-based regimen in FESS, in a population with a relatively high risk of intense surgical field bleeding as determined by baseline characteristics and surgical indication. The effect on surgical field bleeding was significant in the first two hours of the procedure, and did not raise any safety concerns; however, it did not reduce surgical time or obtain lower rates of post-surgical complications.

Considering that clonidine is an inexpensive drug, future clinical guidelines and procedures should consider its use for general anaesthesia in FESS, especially in procedures scheduled to last less than two hours.

\section{Acknowledgement}

Statistical advice: F. Torres (Biostatistics Unit, School of Medicine, Universitat Autònoma de Barcelona, Bellaterra (Barcelona), Spain); Study monitoring: R. Vives (Clinical Pharmacology Unit, Hospital de Sabadell, Institut Universitari Parc Taulí, Universitat Autònoma de Barcelona, Sabadell (Barcelona), Spain); Surgery and data collection: A. Martínez, L. Samarà, A. Aguilà, J.J. Díaz, J. Saiz, E. Bargués (Dept. of Otorhinolaryngology, Hospital de Sabadell, Institut Universitari Parc Taulí, Universitat Autònoma de Barcelona, Sabadell (Barcelona), Spain); Anaesthesia and data collection: S. López, M. Basso (Dept. of Anaesthesia, Hospital de Sabadell, Institut Universitari Parc Taulí, Universitat Autònoma de Barcelona, Sabadell (Barcelona), Spain); Manuscript assistance: J. Sáez (Clinical Pharmacology, Hospital Clinic, Barcelona, Spain).

The study was funded by a grant of Fundació Parc Taulí, Sabadell (Barcelona), Spain: Beques Taulí de Recerca i d'Innovació 2011.

\section{Author contributions}

AC: Principal investigator, study design, data collection, manuscript writing; CP: Study design and analysis, manuscript writing; RR, YE, JM, MJE: collaborating investigators, manuscript review; MBS: study analysis and manuscript writing.

\section{Conflict of interest}

There are no financial conflicts of interest.

\section{References}

1. Fokkens WJ, Lund VJ, Mullol J, Bachert C, Alobid I, Baroody F, et al. EPOS 2012 European position paper on rhinosinusitis and nasal polyps 2012. A summary for otorhinolaryngologists. Rhinology. 2012 50: 1-12

2. Stankiewicz JA1, Lal D, Connor M, Welch K Complications in endoscopic sinus surgery for chronic rhinosinusitis: a 25-year experience. Laryngoscope. 2011; 121: 2684-2701.

3. Pundir V, Pundir J, Georgalas CH, Fokkens W.J. Role of tranexamic acid in endoscopic sinus surgery-A systematic review and meta-analysis. Rhinology. 2013; 51: 291-297.

4. Moshaver A, Lin D, Pinto R, Witterick IJ. The hemostatic and hemodynamic effects of epinephrine during endoscopic sinus surgery: a randomized clinical trial. Arch Otolaryngol Head Neck Surg. 2009; 135: 1005-1009.

5. Yang JJ, Li WY, Jil Q, et al. Local anaesthesia for functional endoscopic sinus surgery employing small volumes of epinephrinecontaining solutions of lidocaine produces profound hypotension. Acta Anaesthesiol Scand. 2005; 49: 1471-1476.

6. Ko MT, Chuang KC, Su CY. Multiple analyses of factors related to intraoperative blood loss and the role of reverse Trendelenburg position in endoscopic sinus surgery. Laryngoscope. 2008; 118: 1687-1691.

7. Rodríguez A, Roldán A, Laguna D. Bleeding control in endoscopic sinus surgery: a systematic review of the literature. Rhinology. 2013; 51: 253-258.

8. Rathjen T, Bockmühl U, Greim CA. Modern anesthesiologic concepts supporting paranasal sinus surgery. Laryngorhinootologie. 2006; 85: 20-23.

9. Eberhart LH1, Folz BJ, Wulf H, Geldner G Intravenous anesthesia provides optimal surgical conditions during microscopic and endoscopic sinus surgery. Laryngoscope. 2003; 113: 1369-1373

10. Tirelli G, Birgarini S, Russolo M, Lucangelo U, Gullo A. Total intravenous anaesthesia in endoscopic sinus-nasal surgery. Acta Otorhinolaryngol Ital. 2004; 24: 137-144

11. Wawrzyniak K, Kusza K, Cywinski JB, Burduk PK, Kazmierczak W. Premedication with clonidine before TIVA optimizes surgical field visualization and shortens duration of endoscopic sinus surgery-results of a clinical trial. Rhinology. 2013; 51: 259-264.

12. Degoute CS. Controlled hypotension: a guide to drug choice. Drugs. 2007; 67: 10531076 .

13. Marchal JM, Gómez-Luque A, MartosCrespo F, et al. Clonidine decreases intraoperative bleeding in middle ear microsurgery. Acta Anaesthesiol Scand. 2001; 45 627-633.

14. Bergendahl H, Lönnqvist PA, Eksborg S Clonidine in paediatric anaesthesia: review of the literature and comparison with benzodiazepines for premedication. Acta Anaesthesiol Scand. 2006; 50: 135-143.

15. Durmus M, But AK, Dogan Z, Yucel A, Miman MC, Ersoy MO. Effect of dexmedetomidine on bleeding during tympanoplasty or septorhinoplasty. Eur J Anaesthesiol. 2007: 24: 447-453.

16. Guven DG, Demiraran Y, Sezen G, Kepek
O, Iskender A. Evaluation of outcomes in patients given dexmedetomidine in functional endoscopic sinus surgery. Ann Otol Rhinol Laryngol. 2011; 120: 586-592.

17. Miłoński J1, Zielińska-Bliźniewska $H_{1}$ Sobański R, Olszewski J. The comparison of the influence of various types of anaesthesia on perioperative bleeding control in endoscopic paranasal sinus surgery. Otolaryngol Pol. 2012; 66: 122-125.

18. Wormald PJ, van Renen G, Perks J, Jones JA, Langton-Hewer CD. The effect of the total intravenous anaesthesia compared with inhalational anaesthesia on the surgical field during endoscopic sinus surgery. Am J Rhinol. 2005; 19: 514-520.

19. Lee J, Kim Y, Park C, J, et al. Comparison between dexmedetomidine and remifentanil for controlled hypotension and recovery in endoscopic sinus surgery. Ann Otol Rhinol Laryngol. 2013; 122: 421-426.

20. Richa F, Yazigi A, Sleilaty G, Yazbeck P. Comparison between dexmedetomidine and remifentanil for controlled hypotension during tympanoplasty. Eur J Anaesthesiol. 2008; 25: 369-374

21. Mugni MG. Clonidina versus fentanilo in epidural in Caesarean: advantages and disadvantages. Doctoral thesis 2007. Universidad Nacional de Córdoba, Spain. Facultad de Ciencias Médicas. Córdoba. ID: 479553.

22. Cardesín A, Pontes C, Rosell R, et al. Hypotensive anaesthesia and bleeding during endoscopic sinus surgery: an observational study. Eur Arch Otorhinolaryngol. 2014: 271: 1505-1511. 
23. Abramson JH. WINPEPI updated: computer programs for epidemiologists, and their teaching potential. Winpepi version 2.67. Epidemiologic Perspectives \& Innovations 2011, 8:1 doi:10.1186/1742-5573-8-1. Consulted on April 16th 2012 at http:// www.brixtonhealth.com/pepi4windows html.

24. Boezaart AP, van der Merwe J, Coetzee A. Comparison of sodium nitroprusside- and esmolol-induced controlled hypotension for functional endoscopic sinus surgery. Can J Anaesth. 1995; 42: 373-376.

25. Wormald PJ, van Renen G, Perks J, Jones JA, Langton-Hewer CD. The effect of the total intravenous anesthesia compared with inhalational anesthesia on the surgical field during endoscopic sinus surgery. Am J Rhinol. 2005; 19: 514-520.

26. Ahn HJ, Chung SK, Dhong HJ, et al. Comparison of surgical conditions during propofol or sevoflurane anaesthesia for endoscopic sinus surgery. Br J Anaesth. 2008; 100: 50-54.

27. Thwin M, Weitzel EK, McMains KC, et al Validating the use of report-derived LundMackay scores. Am J Rhinol Allergy. 2009; 23: 33-35.

28. Rivera Palma LM, Morales Gaytan J, Villarreal Guzmán RA. Comparative trial between clonidine and propranolol in patients who are submitted to rhinoseptoplasty. Rev Sanid Milit Mex. 1997; 51: 218-221.

29. Athanasiadis T, Beule A, Embate J, Steinmeier E, Field J, Wormald PJ.
Standardized video-endoscopy and surgical field grading scale for endoscopic sinus surgery: a multi-centre study. Laryngoscope. 2008; 118: 314-319.

30. Fanini D, Poglio M, Marci MC, Iovinelli G, Antenucci F. Oral premedication with clonidine as an alternative in dental practice. The effects on the pain threshold, blood pressure and salivary flow. Minerva Stomatol. 1998; 47: 453-464.

31. Simoni RF, Cangiani LM, Pereira AM, Abreu MP, Cangiani LH, Zemi G. Efficacy of intraoperative methadone and clonidine in pain control in the immediate postoperative period after the use of remifentanil. Rev Bras Anestesiol. 2009; 59: 421-430.

32. Mortuari G, Bahij J, Maetz B, Chevalier D. Lund-Mackay score is predictive of bleeding in ethmoidectomy for nasal polyposis. Rhinology. 2008; 46: 285-288.

33. Ebert TJ, Ficke DJ, Arain SR, Holtz MN, Shankar H. Vasodilation from sufentanil in humans. Anesth Analg. 2005; 101: $1677-$ 1680.

34. Poree LR1, Guo TZ, Kingery WS, Maze M. The analgesic potency of dexmedetomidine is enhanced after nerve injury: a possible role for peripheral alpha2-adrenoceptors. Anesth Analg. 1998; 87: 941-948.

35. Wing LM, Reid JL, Davies DS, Dargie $\mathrm{HJ}$ Dollery CT. Apparent resistance to hypotensive effect of clonidine. Br Med J. 1977; 15; 1(6054): 136-138.

36. Davies DS, Wing AM, Reid $J L$, Neill DM, Tippett P, Dollery CT. Pharmacokinetics and concentration-effect relationships of intervenous and oral clonidine. Clin Pharmacol Ther. 1977; 21: 593-601.

37. Wawrzyniak K, Kusza K, Cywinski JB, Burduk PK, Kazmierczak W. Premedication with clonidine before TIVA optimizes surgical field visualization and shortens duration of endoscopic sinus surgery - results of a clinical trial. Rhinology. 2013; 51: 259-264.

38. Mohseni M, Ebneshahidi A. The effect of oral clonidine premedication on blood loss and the quality of the surgical field during endoscopic sinus surgery: a placebocontrolled clinical trial. J Anesth. 2011; 25: 614-617.

\section{Caridad Pontes}

Clinical Pharmacology Unit

Hospital de Sabadell

Institut Universitari Parc Taulí

Universitat Autònoma de Barcelona

Sabadell (Barcelona)

Spain

Tel: +34-93-745 8250

Fax: +34-93-716 5049

E-mail: cpontes@tauli.cat 